\title{
Virtual Simulation of Temperature Distribution throughout Beef Packages with Time-temperature Indicator (TTI) Labels
}

\author{
Min-Jung Kim, Sang-Gi Min ${ }^{1}$, and Seung Ju Lee* \\ Department of Food Science and Technology, Dongguk University-Seoul, Seoul 100-715, Korea \\ ${ }^{1}$ Department of Food Science and Biotechnology of Animal Resources, Konkuk University, Seoul 143-701, Korea
}

\begin{abstract}
If the time-temperature indicator (TTI) experienced a different temperature than the accompanied packaged food, influenced by heat transfer between the TTI, package, and ambient air, TTI would incorrectly predict the food quality changes with temperature. Temperature distributions of a finite slab with different sizes, representing beef packaged with TTI, were estimated by the finite element method (FEM). The thermal properties of the beef and TTI, such as heat capacity, density, and heat conductivity, were estimated from the relevant equations using their chemical compositions. The FEM simulations were performed for three cases: different locations of TTIs on the beef, different thicknesses of beef, and non-isothermal conditions of ambient air. The TTIs were mounted in four different locations on the beef. There was little difference in temperature between four locations of the TTI on the package surface. As the thickness of the slab increased, the temperature of the TTI changed faster, followed by the corner surface, as well as middle and bottom parts, indicating the possible error for temperature agreement between the TTI and the slab. Consequently, it was found that any place on the package could be selected for TTI attachment, but the package size should carefully be determined within a tolerable error of temperature.
\end{abstract}

Key words: time-temperature indicator (TTI), temperature distribution, response time, unsteady heat transfer, finite element method (FEM)

\section{Introduction}

A successful indicator known as the time-temperature indicator (TTI) shows certain colors representing accompanying food quality under time-temperature experiences during storage (Bobelyn et al., 2006; Kerry et al., 2006; Lee and Lee, 2008; Vailkousi et al., 2009). TTIs can be mounted on food packages and their configurations can differ according to package size and geometry. As for fish packages, TTIs have been attached on the outside, inside, and center of the package box (Giannakourou et al., 2005). However, depending on the location of the TTI and the geometric condition of the package, the temperatures that the TTI and package experience would be different due to heat transfer between the surrounding air, TTI, and food package, all having different thermal properties. Unfortunately, any attempt in this aspect has not been reported, even though TTI has been known for a long time. There-

\footnotetext{
*Corresponding author: Seung Ju Lee, Department of Food Science and Technology, Dongguk University-Seoul, Seoul 100715, Korea. Tel: 82-2-2260-3372, Fax: 82-2-2260-3372, E-mail: lseungju@dongguk.edu
}

fore, examinations are necessary to determine how temperatures differ by conditions of TTIs and attached packages in terms of size, geometry, and thermal properties.

TTIs can be classified into diffusion, polymer, microbial and enzymatic TTIs. Diffusion based TTIs are dependent on the diffusion system of a coloured chemical substance such as an ester, along a porous wick designed from blotting paper. Polymer based TTIs operate by polymerization reactions in which colorless diacetylene crystals polymerize via 1,4 addition polymerization to a highly coloured polymer. Microbial TTI has irreversible color change due to a $\mathrm{pH}$ decrease as a result of microbial growth and metabolism of the growth medium (Ellouze et al., 2008; Vaikousi et al., 2009). Enzymatic TTIs are the most commonly used for many reasons (Mehauden et al., 2007). This indicator consists of two separate compartments. One compartment contains an aqueous solution of lipolytic enzymes such as pancreatic, and another contains the lipid substrate suspended in an aqueous medium and a $\mathrm{pH}$ indicator mix. Since TTIs, especially the enzymatic type, contain some mass, the TTI mass may influence heat transfer by its use on packages. Although TTI locations on packages can affect heat transfer, a center 
TTI may represent the center and a corner surface TTI may represent the corner side of a package.

A sensor is defined as a device used to detect, locate, or quantify energy or matter, giving a signal for the detection or measurement of a physical or chemical property to which the device responds (Floury et al., 2008; KressRogers, 1998). Sensor performance is typically evaluated in terms of sensitivity, range, resolution, and response time, etc. Sensitivity is the minimum input of a physical signal that will create a detectable output range. The range indicates the maximum and minimum values of the applied parameter that can be measured. Resolution is the minimum detectable signal fluctuation of the input parameter that can be detected in the output signal (Kenny, 2005). Lastly, the response time can be defined as the time required for the sensor output to change from its previous state to a final settled value. In temperature measurements, response time is influenced by the size and shape of the sensor and thermal properties of the objects (Alabbas et al., 1996). Even in TTI applications, the geometrical conditions and thermal properties of TTIs and food packages can affect the response times of TTIs and food packages to surrounding air temperature during storage.

As a result, experiments should be performed to determine if there are differences in temperature between TTIs and packages during storage. The temperatures throughout a package should be different, in other words, a TTI can only represent its attached location. The heat transfer in a package, if large enough, is governed by internal resistance rather than external resistance. In fact, these internal and external resistances can be differentiated by Biot numbers $\left(\mathrm{N}_{\mathrm{Bi}}=\right.$ internal resistance to heat transfer/ external resistance to heat transfer). If $\mathrm{N}_{\mathrm{Bi}}<0.1$, heat transfer is governed by external resistance; if $0.1<\mathrm{N}_{\mathrm{Bi}}<40$, heat transfer is governed by both external and internal resistance; and if $\mathrm{N}_{\mathrm{Bi}}>40$, heat transfer is governed by internal resistance (Batty and Folkman, 1983). In particular, when governed by internal resistance, the object size is significantly large like in regular TTI mounted packages. Incidentally, thermal properties such as conductivity, heat capacity, density, and heat transfer coefficient between an object and ambient air also influence internal resistance. If there are significant differences between the temperatures that a TTI and food experience due to factors of internal resistance, food quality would be incorrectly predicted from the TTI.

Predictions of temperature change with respect to time and location under unsteady state conditions are usually resolved by numerical methods rather than analytical methods (Nicolai et al., 2001). The finite element method (FEM) is a commonly used technique that can manage irregular geometries, analyze non-homogeneous and nonisotropic food products, and is generally more accurate (Pandit and Prasad, 2003; Puri and Anantheswaran, 1993). FEM was initially applied in the stress analysis of complicated constructions, and then evolved to versatile solutions for fluid and solid mechanics, and heat and mass transfer. Particularly in food areas, FEM can provide successful solutions for cooking, cooling, thawing, microwave heating, etc (Wang and Sun, 2002a). Chen et al. (1993) and Pandit and Prasad (2003) predicted the temperature distribution of potatoes during microwave heating by using FEM. Wang and Sun (2002b) used FEM to evaluate the performance of slow air, air blast, and water immersion cooling methods for various sizes of meat. Santos et al. (2010) found the optimum heating conditions for minimizing E. coli $\mathrm{O} 157: \mathrm{H} 7$ levels in sausage by simulating the temperature of sausage during heating using FEM. FEM has been widely applied to the freezing of beef (Sun and Zhu, 1999), frying of sweet potato (Farinu and Baik, 2008), drying of carrots (Aversa et al., 2007), thawing of model food substances (Abdalla et al., 1985), and the distribution and storage of grain (Jia et al., 2000). Overall, FEM provides practical numerical solutions for heat transfer related subjects.

In this study, we attempted to analyze possible differences in temperature between TTIs and food packages during storage. The temperatures were mathematically simulated by FEM under conditions of different food package sizes and TTI locations on packages, as well as dynamic ambient air temperatures. Temperature response times were also used to examine temperature discrepancies. A fictitious food and an enzymatic TTI based on a lipase-triglyceride mixture (Yoon et al., 1994) were used. The thermal properties of the food and TTI were calculated using empirical equations (Choi and Okos, 1985).

\section{Materials and Methods}

It was assumed that the fictitious TTI and food package systems would be exposed to ambient air and the surface put at the bottom insulated. Temperature distributions were calculated with FEM throughout the system according to storage time. The examined temperature spots in the food package (a fictitious beef) are shown in Fig. 1. TTIs (fictitious TTI referenced from Yoon et al. (1994)) were located in various places on the food package as shown in Fig. 2. 


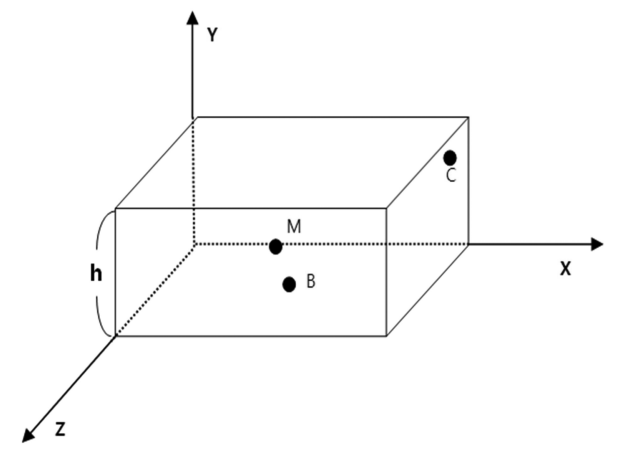

Fig. 1. Measured locations on beef package. $M$, middle; $B$, bottom; C, corner surface; h, variable size of beef package (thickness).

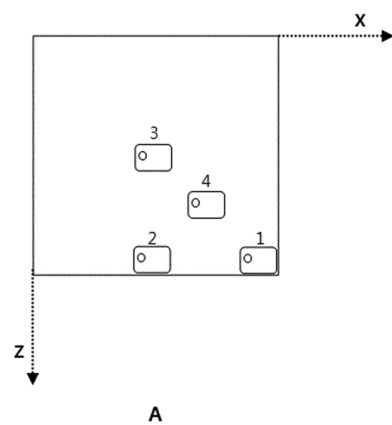

A

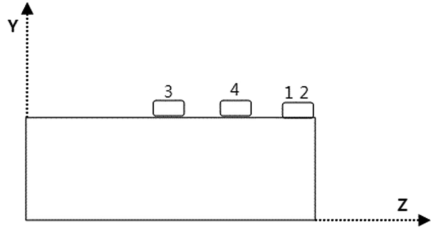

B
Fig. 2. Locations of TTIs mounted on beef package. A, top view; B, side view. 1 , corner surface; 2 , center side; 3 , center; 4 , middle.
Table 1. Composition of TTI and beef

\begin{tabular}{lclc}
\hline \hline \multicolumn{1}{c}{ TTI } & Amount $^{1)}$ & \multicolumn{1}{c}{ Beef } & Amount $^{2)}$ \\
\hline Buffer & $15 \mathrm{~g}$ & Water & $70.2 \mathrm{~g}$ \\
Substrate (olive oil) & $18.3 \mathrm{~g}$ & Protein & $20.7 \mathrm{~g}$ \\
Antifreeze agent (glycerol & $64.7 \mathrm{~g}$ & Fat & $7.26 \mathrm{~g}$ \\
$\quad$ 18.9 g, sorbitol 45.8 g) & & & \\
pH-indicator mixture & $12.1 \mathrm{~g}$ & Ash & $1.04 \mathrm{~g}$ \\
Emulsifier & $0.5 \mathrm{~g}$ & & \\
\hline
\end{tabular}

${ }^{1)}$ Referenced from Yoon et al. (1994).

${ }^{2)}$ Referenced from nutritional website http://www.calorie-counter. net/beef-calories/beef-sirloin.htm

\section{Determination of thermal properties of the materials}

The thermal properties of the beef, such as heat capacity, density, and heat conductivity, were estimated from relevant equations (Table 2) using its chemical composition (Table 1). The thermal properties of the TTI were calculated in the same manner using its chemical composition (Table 1). In the lipase-triglycerides system, the mixture was composed of buffer (assumed as water), substrate (as a fat), antifreeze agent (as a mixture of fat and carbohydrate), $\mathrm{pH}$-indicator mixture (as water), and emulsifier (as a fat). For the thermal conductivity, there were two types of arrangements of the mixture foods: parallel and series. The series was adopted because beef

Table 2. Thermal properties of components of beef and TTI as functions of temperature

\begin{tabular}{|c|c|c|}
\hline & Component & Equation \\
\hline \multicolumn{3}{|l|}{ Density } \\
\hline \multirow{5}{*}{$\rho=\frac{1}{\sum \frac{w_{i}^{1)}}{\rho_{i}}}$} & Carbohydrate & $\rho=1.5991 \cdot 10^{3}-0.31046 \cdot T$ \\
\hline & Ash & $\rho=2.4238 \cdot 10^{3}-0.28063 \cdot T$ \\
\hline & Fat & $\rho=9.2559 \cdot 10^{3}-0.41757 \cdot T$ \\
\hline & Protein & $\rho=1.3299 \cdot 10^{3}-0.51840 \cdot T$ \\
\hline & Water & $\rho=997.18+3.1439 \cdot 10^{-3} \cdot T-3.7574 \cdot 10^{-3} \cdot T$ \\
\hline \multicolumn{3}{|l|}{ Specific heat } \\
\hline \multirow{5}{*}{$C_{p}=\sum C_{p i} w_{i}$} & Carbohydrate & $C_{p}=1.5488+1.9625 \cdot 10^{-3} \cdot T-5.9399 \cdot 10^{-6} \cdot T^{2}$ \\
\hline & Ash & $C_{p}^{p}=1.0926+1.8896 \cdot 10^{-3} \cdot T-3.6817 \cdot 10^{-6} \cdot T^{2}$ \\
\hline & Fat & $C_{p}^{p}=1.9842+1.4733 \cdot 10^{-3} \cdot T-4.8008 \cdot 10^{-6} \cdot T^{2}$ \\
\hline & Protein & $C_{p}=2.0082+1.2089 \cdot 10^{-3} \cdot T-1.3129 \cdot 10^{-6} \cdot T^{2}$ \\
\hline & Water & $C_{p}=4.1762-9.0864 \cdot 10^{-3} \cdot T-5.4731 \cdot 10^{-6} \cdot T^{2}$ \\
\hline \multicolumn{3}{|l|}{ Thermal conductivity } \\
\hline \multirow{5}{*}{$k=\frac{1}{\sum_{i=1}^{N} \frac{\emptyset_{i}}{k_{i}}}$} & Carbohydrate & $k=0.20141+1.3874 \cdot 10^{-3} \cdot T-4.3312 \cdot 10^{-6} \cdot T^{2}$ \\
\hline & Ash & $k=0.32962+1.4011 \cdot 10^{-3} \cdot T-2.9069 \cdot 10^{-6} \cdot T^{2}$ \\
\hline & Fat & $k=0.18071+2.7604 \cdot 10^{-3} \cdot T-4.3312 \cdot 10^{-6} \cdot T^{2}$ \\
\hline & Protein & $k=0.17881+1.1958 \cdot 10^{-3} \cdot T-2.7178 \cdot 10^{-6} \cdot T^{2}$ \\
\hline & Water & $k=0.57109+1.7625 \cdot 10^{-3} \cdot T-6.7036 \cdot 10^{-6} \cdot T^{2}$ \\
\hline
\end{tabular}

Volume fraction

$$
\emptyset_{i}=\frac{w_{i} / \rho_{i}}{\sum\left(w_{i} / \rho_{i}\right)}
$$


is a mixture of many dispersed components, and therefore, is close to configuration in series (Neethirajan et al., 2009).

\section{Numerical analysis}

The numerical analysis was executed by ANSYS (10.0, ANSYS Inc., USA) and the conditions are shown in Table 3. The procedure was to first build model, set load, and finally solve and analyze.

In Table 3, the initial temperature conditions of the beef and TTI were assumed to be $0^{\circ} \mathrm{C}$ the same. The bottom of the beef was assumed to be insulated, and the surface of the beef with an attached TTI was assumed to be in natu- ral convection heat transfer mode with a convective heat transfer coefficient of $17 \mathrm{~W} / \mathrm{m}^{2} \cdot \mathrm{K}$. The heat transfer resistance in the interface of the TTI and beef, i.e., a packaging film, was neglected.

Simulations were performed for three cases: different locations of TTIs on the beef, different thicknesses of beef, and non-isothermal conditions of ambient air. The TTIs were mounted in four different locations on the beef (Fig. 2). The size of the beef was assumed to be $10 \mathrm{~cm}$ by $10 \mathrm{~cm}$ in length and width, and with various thicknesses of $1.5,3$, and $5 \mathrm{~cm}$. The TTI size was fixed as that of a regular commercial TTI (CheckPoint TTI by the VITSAB Company, Sweden) with 2, 2, and $0.2 \mathrm{~cm}$ for length,

\section{Table 3. Steps of ANSYS program for simulation}

\begin{tabular}{|c|c|c|}
\hline \multicolumn{2}{|c|}{ Analysis phases } & Given conditions \\
\hline \multirow{5}{*}{ Building model } & Element type & $\begin{array}{l}\text { SOLID70 representing a brick type was chosen for beef and TTI; contact manager was } \\
\text { used to analyze surface-to-surface. }\end{array}$ \\
\hline & Real constants & The same real constants on the interface were shared by TTI and beef. \\
\hline & Material properties ${ }^{1)}$ & $\begin{array}{l}\text { The thermal properties such as density, specific heat, and thermal conductivity in Table } 2 \\
\text { for TTI and beef were used. }\end{array}$ \\
\hline & Modeling & $\begin{array}{l}\text { Finite slab model was adopted for beef and TTI, and TTI was mounted on beef as shown } \\
\text { in Fig. } 2 .\end{array}$ \\
\hline & Meshing & Mapped meshing was used for individual volumes. \\
\hline \multirow{3}{*}{ Solution } & Analysis type & It was confined to transient heat transfer ${ }^{2)}$. \\
\hline & Define loads & $\begin{array}{l}\text { The boundary conditions such as initial temperatures of beef and TTI, time step size } \\
\text { according to steady and dynamic profile }{ }^{3)} \text {, ambient air temperature and convective heat } \\
\text { transfer coefficient }{ }^{4)}\end{array}$ \\
\hline & Solve & - \\
\hline
\end{tabular}
Temperature distributions throughout the nodes according to storage times

${ }^{1)}$ Isotropic

${ }^{2)}$ This means unsteady heat transfer mode.

${ }^{3)}$ Time step size $=\beta(\rho \mathrm{c} \Delta \mathrm{x} / \mathrm{h}), 0.1 \leq \beta \leq 0.5\left(\mathrm{~N}_{\mathrm{Bi}}>1\right)$. $\rho$, average density; $\mathrm{h}$, heat transfer coefficient; $\mathrm{c}$, specific heat; $\Delta \mathrm{x}$, average size of element.

${ }^{4)}$ Air temperatures are set for static condition or dynamic conditions (Fig. 3), respectively.
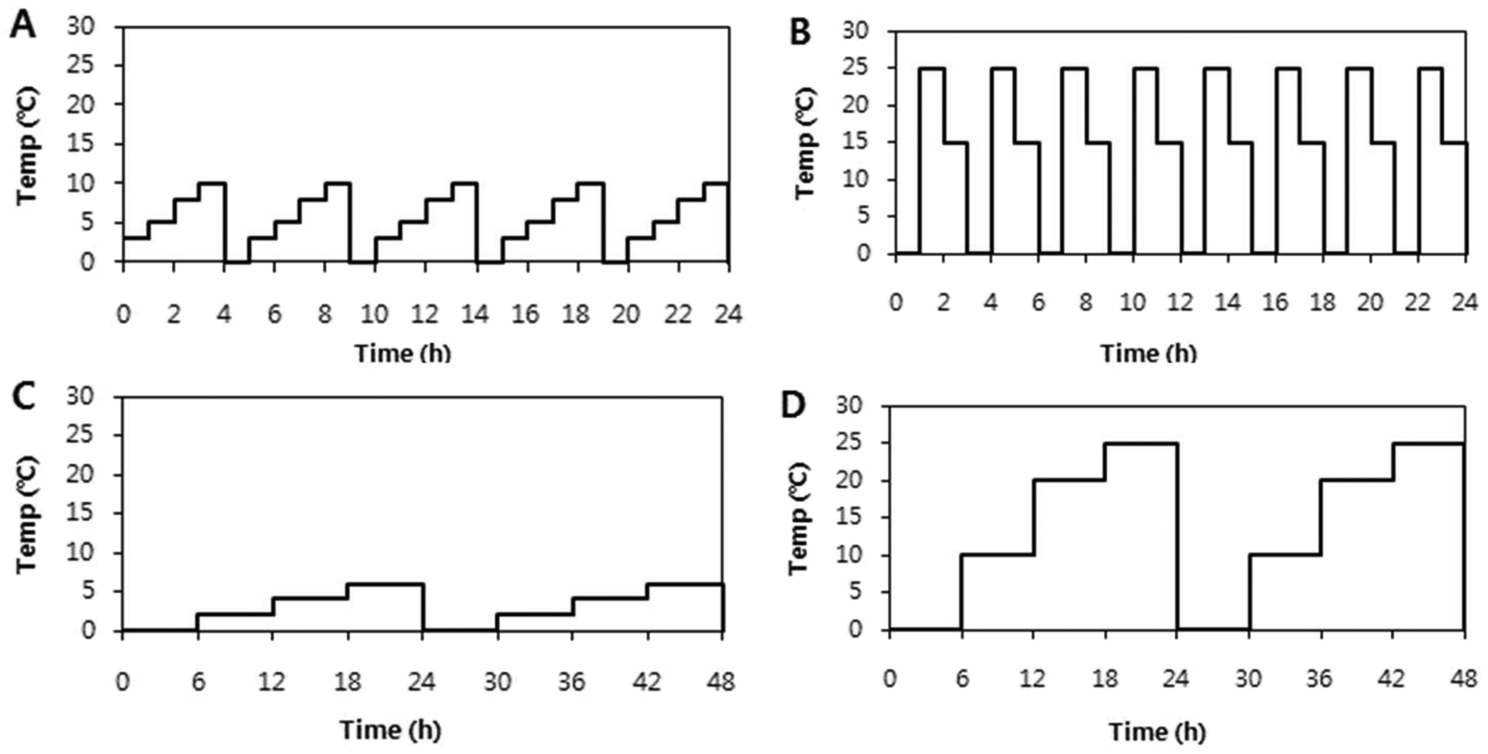

Fig. 3. Time-temperature profiles under dynamic condition. A, case I; B, case II; C, case III; D, case IV. 
width, and thickness, respectively. The non-isothermal air conditions were set as the profiles in Fig. 3, reflecting four possible storage conditions. Case I and II represented several paths during transportation, which involved more frequent temperature fluctuations. Case III and IV represented paths during storage, involving less frequent fluctuations (Park et al., 2009). Also, by cases II and IV, we intended to observe the effects of the temperature amplitudes. Meanwhile, the simulations for the different TTI locations on the beef and different beef thicknesses were under isothermal air conditions at $25^{\circ} \mathrm{C}$.

\section{Determination of response time}

There are several performance factors for sensors: sensitivity, range, resolution, and response time. In particular, response time is influenced by heat transfer according to the size and configuration of the sensors and target materials, representing a time delay before reaching a set temperature (Alabbas et al., 1996). There are several ways to define response time, but here, response time was defined as the time taken to reach $70 \%$ of the total temperature range from the initial temperature $0^{\circ} \mathrm{C}$ to the final temperature equivalent to ambient air temperature $25^{\circ} \mathrm{C}$ (Datskos and Lavrik, 2004).

\section{Results and Discussion}

For each case of various beef package size, the contours of temperature distribution, which were calculated using FEM. In conditions such as same ambient air temperature, the temperature of the beef package differs depending on its size at the same time. More quantitative results are as follows.

\section{Effects of TTI locations mounted on package}

Fig. 4 shows temperature changes with time according to TTI locations on the beef. The locations on the three dimensional $\mathrm{X}, \mathrm{Y}, \mathrm{Z}$-coordinates were $(8 \mathrm{~cm}, 3 \mathrm{~cm}, 8$ $\mathrm{cm}),(4 \mathrm{~cm}, 3 \mathrm{~cm}, 8 \mathrm{~cm}),(4 \mathrm{~cm}, 3 \mathrm{~cm}, 4 \mathrm{~cm})$, and $(7 \mathrm{~cm}$, $3 \mathrm{~cm}, 6 \mathrm{~cm})$ for the surfaces at the corner surface $(1 \mathrm{in}$ Fig. 2), center side (2), center (3), and middle (4), respectively. There were only small differences between the locations of around $0.1^{\circ} \mathrm{C}$. This indicates that the presence of the beef, which has not uniform temperature distribution throughout the body in unsteady state, might not influence the TTI temperature changes because the two materials have different thermal properties, particularly a lower heat capacity for the TTI as well as a much smaller size compared to the beef. Consequently, the TTI internal

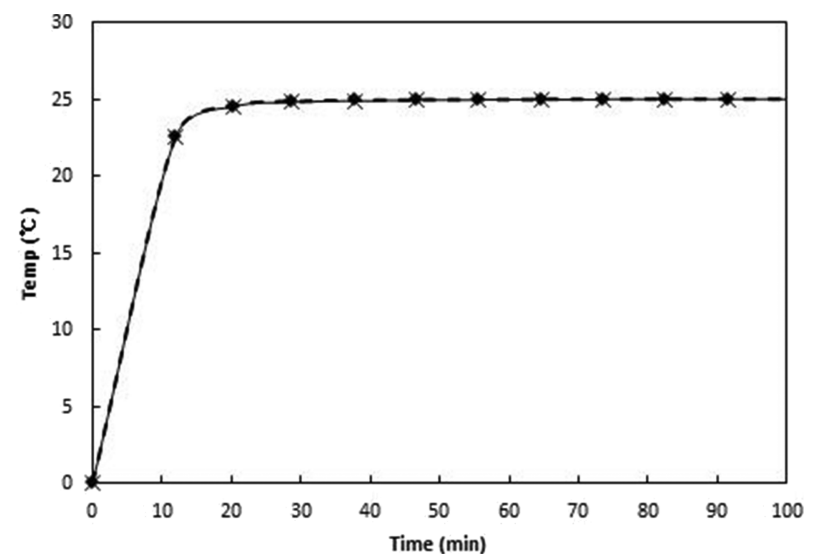

Fig. 4. Plots of temperature vs. time for TTIs mounted on different locations of beef package. ---, location 1 ; $\diamond$, location $2 ;-$, location $3 ; \times$, location 4 .

resistance to heat transfer is negligible so that the convective heat transfer with the ambient air becomes dominant (Batty and Folkman, 1983).

If the TTI has similar thermal properties to the beef, the center would have a lower temperature change than the corner surface. Still this reasoning supports that the TTI seems to be independent of the beef in terms of response time, although the TTI was attached to the beef, resulting in little efficacy by TTI location on the beef in terms of response time. Therefore, when packaging with a TTI, the TTI does not have to be fixed at a certain location.

\section{Effects of package size under isothermal conditions}

The fastest temperature change with time occurred at the corner surface for all beef thickness conditions, followed by the middle and bottom parts in increasing order (Fig. 5). Response time was read as the time to reach $17.5^{\circ} \mathrm{C}$. The TTIs had response times of $5.05,9.3$, and $13.56 \mathrm{~min}$, much shorter than those of the corner surface, e.g., $13.3 \mathrm{~min}$ for the $1.5 \mathrm{~cm}$ beef thickness. This is because the TTIs were much smaller in size and lower in heat capacity than the beef, and therefore, temperature responses were faster. Regarding the effects of location, the times taken to reach $17.5^{\circ} \mathrm{C}$ for the $1.5 \mathrm{~cm}$ thick beef were 13.3, 19.3, and 19.7 min for the corner surface, middle, and bottom, respectively. This indicates that the heat transfer is lower at the more inner locations (Wang and Sun, 2002a; Wang and Sun, 2002b). For the $3 \mathrm{~cm}$-thick beef, they were $20.4,32$, and $32.5 \mathrm{~min}$, respectivly, and for the $5 \mathrm{~cm}$-thick beef, they were 26.66, 42.7, and 43.8 min, respectivley. According to this, the heat transfer rate increased with beef thickness, because the internal heat resistance through the beef increased with thickness. 

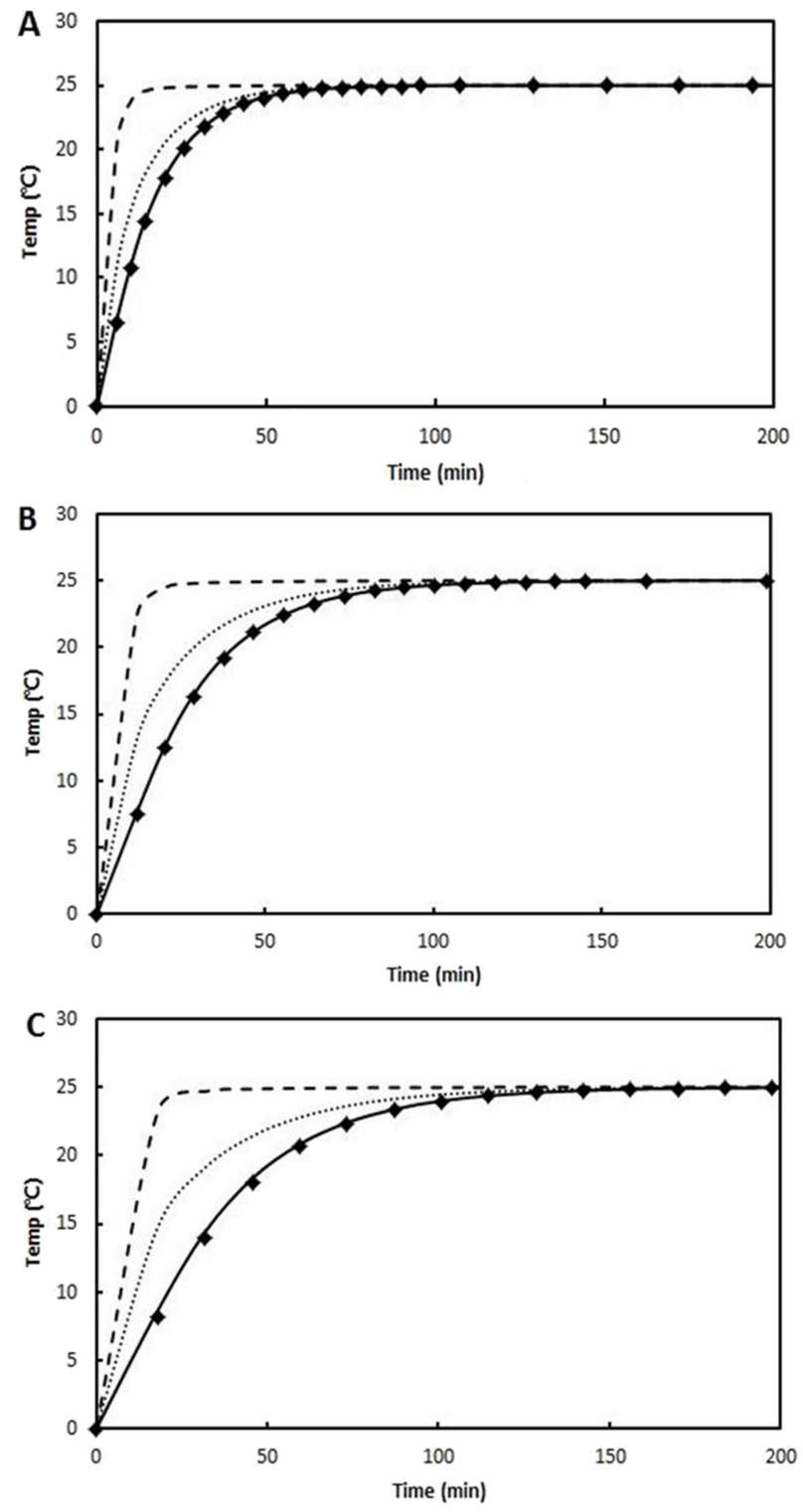

Fig. 5. Plots of temperature vs. time for variable locations on different sized beef packages and TTI mounted on the corner surface under isothermal air conditions at $25^{\circ} \mathrm{C}$. A, h=1.5 cm (case II); B, h=5 cm (case II); C, $\mathrm{h}=1.5 \mathrm{~cm}$ (case III); D, h=5 cm (case III). ---, TTI; ….., corner surface; - , middle; $\diamond$, bottom.

\section{Effects of package size under dynamic temperature conditions}

The beef with thicknesses of $1.5,3$, and $5 \mathrm{~cm}$ and a TTI attached at the center surface were mathematically simulated for temperature distribution under non-isothermal storage conditions (Fig. 3). The possible combinations of the conditions were as many as 12 ( 3 thickness $\times 4$ nonisothermal conditions $=12$ ), thus the few with significant differences were selected in the following manner. The small and large beef thicknesses $(1.5 \mathrm{~cm}, 5 \mathrm{~cm})$ were matched with case II [big amplitude and short interval $\left.\left(0^{\circ} \mathrm{C}-25^{\circ} \mathrm{C}, 1 \mathrm{~h}\right)\right]$ and case III [small amplitude and long interval $\left.\left(0^{\circ} \mathrm{C}-5^{\circ} \mathrm{C}, 6 \mathrm{~h}\right)\right]$, respectively. Case II may affect beef quality more due to higher temperature fluctuations, whereas case III would have less change in temperature.

In case II for the $1.5 \mathrm{~cm}$ thick beef, after $20 \mathrm{~min}$ at $25^{\circ} \mathrm{C}$, temperature responses were quick in the order of TTI, corner surface, middle, and bottom parts of the beef, reaching $24.8,20.5,17.8$, and $17.4^{\circ} \mathrm{C}$, respectively (Fig. 6). In case II of the $5 \mathrm{~cm}$-thick beef, the magnitudes of temperature change among the parts were in the same order as for the $1.5 \mathrm{~cm}$-thick beef. However, the temperature response gaps became larger for the three parts of beef, reaching $15.3,9.3$, and $8.9^{\circ} \mathrm{C}$ after $20 \mathrm{~min}$ at $25^{\circ} \mathrm{C}$, respectively. Overall, the temperature changed at a lower rate when compared to the $1.5 \mathrm{~cm}$-thick beef.

In case II for the $1.5 \mathrm{~cm}$-thick beef, after $60 \mathrm{~min}$ at $25^{\circ} \mathrm{C}$ and $20 \mathrm{~min}$ at $15^{\circ} \mathrm{C}$, consecutively, temperature responses were quick in the order of TTI, corner surface, middle, and bottom parts of the beef, reaching 15.1, 16.7, 17.7, and $17.8^{\circ} \mathrm{C}$, respectively. Case II of the $5 \mathrm{~cm}$-thick beef showed the same tendency as that of the $1.5 \mathrm{~cm}$-thick beef for temperature response order among the parts. However, changes in overall temperature were slower than those of the $1.5 \mathrm{~cm}$-thick beef.

In case II for the $1.5 \mathrm{~cm}$-thick beef, after $60 \mathrm{~min}$ at $25^{\circ} \mathrm{C}$, $60 \mathrm{~min}$ at $15^{\circ} \mathrm{C}$, and $60 \mathrm{~min}$ at $0^{\circ} \mathrm{C}$, consecutively, the TTI and the corner surface, middle, and bottom parts of the beef reach $0^{\circ} \mathrm{C}$, whereas in the same situation for the 5 $\mathrm{cm}$-thick beef the TTI reached $0^{\circ} \mathrm{C}$, but the beef did not reach $0^{\circ} \mathrm{C}$, with temperatures of $1.3,2.6$, and $2.7^{\circ} \mathrm{C}$, respectively.

As the size of the beef package became larger, the TTI showed delayed temperature responses. This is because the temperature of the beef influenced that of the attached TTI. However, it should be reiterated that the reason why there was no difference in TTI temperature for the different TTI locations was that the TTI is independent of the beef. Compromising these two understandings that there is dependency between the TTI and beef in terms of heat transfer, the TTI should be governed more by the beef in terms of different sized beef than different TTI locations on the same sized beef.

In case III for the $1.5 \mathrm{~cm}$-thick beef, after $6 \mathrm{~h}$ at $2,4,6$, and $0^{\circ} \mathrm{C}$, respectively, the temperatures reached each target temperature earlier, in the order of TTI, corner surface, middle, and bottom parts of the beef. Even the 5 $\mathrm{cm}$-thick beef reached target temperatures in an intermediate length of time because the time intervals were long enough. As compared to case II, the differences in tem- 

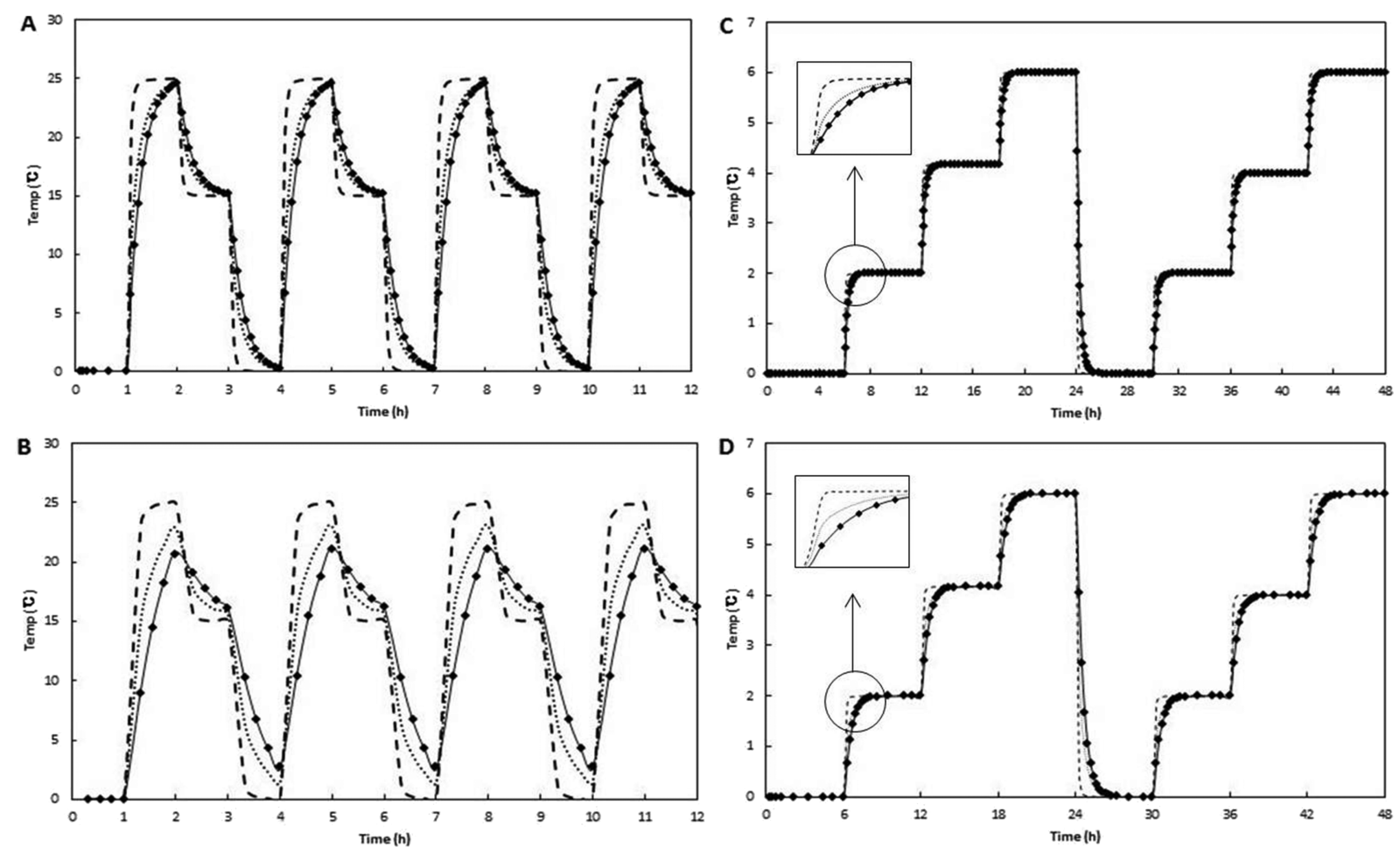

Fig. 6. Plots of temperature vs. time for variable locations on different sized beef packages and TTI mounted on the corner surface under dynamic temperature condions. $\mathrm{A}, \mathrm{h}=1.5 \mathrm{~cm}$ (case II); $\mathrm{B}, \mathrm{h}=5 \mathrm{~cm}$ (case II); C, $\mathrm{h}=1.5 \mathrm{~cm}$ (case III); D, h=5 cm (case III). ---, TTI; ….., corner surface; - , middle; $\bullet$, bottom.

perature between the TTIs and several beef parts were less significant in case III, because the storage conditions were less dynamic in terms of temperature schedule with respect to time.

Consequently, it was found that larger sized beef is slower in temperature response to ambient air temperature. Moreover, various non-isothermal storage conditions result in different temperature responses for TTIs and various parts of beef. For all different sizes of beef, the TTI responded faster than the various parts of the beef, although there was a slight difference in the TTI for different sizes of beef.

TTIs are successful indicators for intelligent food packages, indicating food quality by color changes during storage. In this study, some possible differences between the temperatures as experienced by TTIs and beef packages with TTIs attached were mathematically analyzed. The results showed that TTI could be placed anywhere outside the packages for there were no differences in temperature throughout the package surface. When the slab packages were thicker under more temperature abuse conditions, the temperature histories that the TTI and the packaged food experienced were more different. Accordingly, smaller packages could be fitter for TTI applications than bigger ones. If a relatively big package needs to be used, the strict control of cold-chain would be required with temperature abuse avoided. If the packages are filed up during storage or distribution, each of them should have its own TTI attached to make the temperature histories of TTI and the individual packages the same. Through this study, it was convinced that the thermophysical properties and geometrical conditions of packages including TTI and packaged food should be as important as the kinetics aspects of TTI and food reactions involved which had traditionally been studied. Such consideration would contribute to determine a tolerable condition for TTI use such as the package size, the food composition, the magnitude of temperature fluctuation of ambient air, etc.

\section{Acknowledgement}

This study was supported by the Agriculture Research Center (ARC, 710003-03-1-SB110) program of the Ministry for Food, Agriculture, Forestry and Fisheries, Korea.

\section{References}

1. Abdalla, H. and Paul, S. R. (1985) Simulation of thawing of foods using finite element method. J. Food Process Eng. 7, 
273-286.

2. Alabbas, S. H., Ashwortha, D. C., Bezzaaa, B., Momina, S. A., and Narayanaswamy, R. (1996) Factors affecting the response time of an optical-fiber reflectance $\mathrm{pH}$ sensor. Sensors Actuators A. 51, 129-134.

3. Aversa, M., Curcio, S., Calabro, V., and Iorio, G. (2007) An analysis of the transport phenomena occurring during food drying process. J. Food Eng. 78, 922-933.

4. Batty, J. C. and Folkman, S. L. (1983) Food Engineering Fundamentals. John Wiley \& Sons, Inc.

5. Bobelyn, E., Hertog, M. L. A. T. M., and Nicola, B. M. (2006) Applicability of an enzymatic time temperature integrator as a quality indicator for mushrooms in the distribution chain. Postharvest Biol. Technol. 42, 104-114.

6. Chen, D. D., Singh, R. K., Haghighi, K., and Nelson, P. E. (1993) Finite element analysis of temperature distribution in microwaved cylindrical potato tissues. J. Food Eng. 18, 351368.

7. Choi, Y. and Okos, M. R. (1985) Effects of temperature and composition on the thermal properties of foods. In: Food Engineering and Process Applications, Le Maguer, M. and Jelen, P. (eds) Elsevier Inc., NY, Vol. 1, pp. 93-101.

8. Datskos, P. G. and Lavrik, N. V. (2004) Uncooled infrared MEMS detectors. In: Smart sensors and MEMS. Yurish, S. Y. and Gomes, M. T. S. R. (eds) Kluwer Academic Publishers, Netherlands, Vol. 181, pp. 381-419.

9. Ellouze, M., Pichaud, M., Bonaiti, C., Coroller, L., Couvert, O., Thuault, D., and Vaillant, R. (2008) Modelling pH evolution and lactic acid production in the growth medium of a lactic acid bacterium: application to set a biological TTI. Int. J. Food Microbiol. 128, 101-107.

10. Farinu, A. and Baik, O. D. (2008) Convective mass transfer coefficients in finite element simulations of deep fat frying of sweet potato. J. Food Eng. 89, 187-194.

11. Floury, J., Carson, J., and Phan, Q. T. (2008) Modeling thermal conductivity in heterogeneous media with the finite element method. Food Bioprocess Tech. 1, 161-170.

12. Giannakourou, M. C., Koutsoumanis, K., Nychas, G. J., and Taoukis, P. S. (2005) Field evaluation of the application of time temperature integrators for monitoring fish quality in the chill chain. Int. J. Food Microbiol. 102, 323-336.

13. Jia, C. C., Sun, D., and Cao, C. W. (2000) Finite element prediction of transient temperature distribution in a grain storage bin. J. Agr. Eng. Res. 76, 323-330.

14. Kenny, T. (2005) Sensor fundamentals. In: Sensor Technology Handbook. Wilson, J. S. (ed) Elsevier Inc., UK, pp. 1-20.

15. Kerry, J. P., O'grady, M. N., and Hogan, S. A. (2006) Past, current and potential utilization of active and intelligent packaging systems for meat and muscle-based products: a review. Meat Sci. 74, 113-130.

16. Kress-Rogers, E. (1998) Terms in instrumentation and sensors technology. In: Instrumentation and Sensors for the Food Industry. Kress-Rodgers, E. (ed) Woodhead Publishing
Ltd, UK, pp. 673-691.

17. Lee, J. M. and Lee, S. J. (2008) Kinetic modeling for predicting the qualities of beef and color of enzyme time-temperature integrator during storage. Food Eng. Prog. 12, 241-246.

18. Mehauden, K., Cox, P. W., Bakalis, S., Simmons, M. J. H., Tucker, G. S., and Fryer, P. J. (2007) A novel method to evaluate the applicability of time temperature integrators to different temperature profiles. Innov. Food Sci. Emerg. Tech. 8, 507-514.

19. Neethirajan, S., Jayas, D. S., and Sadistap, S. (2009) Carbon dioxide $\left(\mathrm{CO}_{2}\right)$ sensors for the agri-food industry: a review. Food Bioprocess Tech. 2, 115-121.

20. Nicolai, B. M., Verboven, P., and Scheerlinck, N. (2001) The modeling of heat and mass transfer. In: Food Process Modeling. Tijskens, L. M. N., Hertog, M. L. A. T. M., and Nicolai, B. M. (Eds) Woodhead Publishing Limited, Abington Hall, Abington, Cambridge, CB1 6AH, UK, pp. 60-86.

21. Park, H. J., Shim, S. D., Min, S. G., and Lee, S. J. (2009) Mathematical simulation of the temperature dependence of time-temperature integrator (TTI) and meat qualities. Korean J. Food Sci. An. 29, 349-355.

22. Pandit, R. B. and Prasad, S. (2003) Finite element analysis of microwave heating of potato: transient temperature profile. J. Food Eng. 60, 193-202.

23. Puri, V. M. and Anantheswaran, R. C. (1993) Finite element method in food processing: a review. J. Food Eng. 19, 247274.

24. Santos, M. V., Zaritzky, N., and Califano, A. (2010) A control strategy to assure safety conditions in the thermal treatment of meat products using a numerical algorithms. Food Control 21, 191-197.

25. Sun, D. W. and Zhu, X. (1999) Effect of heat transfer direction on the numerical prediction of beef freezing process. $J$. Food Eng. 42, 45-50.

26. Vaikousi, H., Biliaderis, C. G., and Koutsoumanis, K. P. (2009) Applicability of a microbial time temperature indicator (TTI) for monitoring spoilage of modified atmosphere packed minced meat. Int. J. Food Microbiol. 133, 272-278.

27. Wang, L. and Sun, D. W. (2002a) Modeling three-dimensional transient heat transfer of roasted meat during air blast cooling by the finite element method. J. Food Eng. 51, 319328.

28. Wang, L. and Sun, D. W. (2002b) Evaluation of performance of slow air, air blast and water immersion cooling methods in the cooked meat industry by finite element method. J. Food Eng. 51, 329-340.

29. Yoon, S. H., Lee, C. H., Kim, D. Y., Kim, J. W., and Park, K. H. (1994) Time-temperature indicator using phospholipidphospholipase system and application to storage of frozen pork. J. Food Sci. 59, 490-493.

(Received 2012.9.10/Revised 2012.12.12/Accepted 2013.1.2) 